\title{
Hypocholesterolemic Effect of Ursodeoxycholylcysteic Acid in Hamsters Fed a High Cholesterol Diet
}

\author{
Hideki SHIMIZU, Michiko YOSHII, Atsuko SEKI, Mizuho UNE, and Takahiko HOSHITA \\ Institute of Pharmaceutical Science, Hiroshima University School of Medicine, Kasumi 1-2-3, \\ Minami-ku, Hiroshima, 734, Japan
}

(Received April 30, 1992)

\begin{abstract}
We studied the effect of feeding ursodeoxycholylcysteic acid, the cysteic acid conjugated ana$\log$ of ursodeoxycholyltaurine, on serum and liver cholesterol levels and on intestinal absorption of cholesterol and bile salts in hamsters. Addition of ursodeoxycholylcysteic acid to the cholesterolenriched diet reduced the elevation of serum and liver cholesterol levels caused by feeding cholesterol. However, supplementation with ursodeoxycholylcysteic acid to the standard diet did not show any significant change in serum and liver cholesterol levels. Administration of ursodeoxycholylcysteic acid caused a decrease in dietary cholesterol absorption but did not interfere with the ileal transport of endogenous bile salts. Hence the hypocholesterolemic activity of dietary ursodeoxycholylcysteic acid is thought to be the effect on intestinal absorption of cholesterol but not to be the interruption of the enterohepatic circulation of bile salts.
\end{abstract}

Keywords — ursodeoxycholylcysteic acid; hypocholesterolemic effect; cholesterol absorption; hamster

\section{Introduction}

Ursodeoxycholic acid (UDCA) is the major constituent of the Chinese and Japanese folk medicine, Yutan, a powder prepared from dried gallbladder bile of adult bears. While UDCA is in use as a therapeutic agent for dissolution of cholesterol gallstones in humans, ${ }^{1)}$ this naturally occurring bile acid is recently used to treat patients with primary biliary cirrhosis. ${ }^{2)}$ Studies on both humans ${ }^{3)}$ and rats $^{4)}$ have shown that UDCA feeding caused a significant decrease in dietary cholesterol absorption. These observations suggest that UDCA might be a hypocholesterolemic agent, although in patients with cholesterol gallstones serum cholesterol levels did not show any appreciable change during UDCA feeding. ${ }^{5)}$ Another effective method to decrease blood cholesterol levels is an interruption of the enterohepatic circulation of endogenous bile salts resulting in a feedback stimulation of biosynthesis of bile salts, degradation products of cholesterol. Lack et al. have reported ${ }^{6-8)}$ that bile salts bearing two negative charges in the region of their side chain were capable of inhibiting the bile salt active transport system in the ileum, the major route by which endogenous singly charged bile salts are reabsorbed.

In the present paper we therefore prepared ur- sodeoxycholylcysteic acid (UDC-cysA), which is the cysteic acid conjugated analog of the naturally occurring taurine conjugated bile salt, ursodeoxycholyltaurine, and investigated the effects of feeding of the chemically synthesized dibasic bile salt, UDC-cysA, on serum and liver cholesterol levels and on intestinal absorption of cholesterol and bile salts in hamsters. Our finding shows that administration of UDC-cysA caused a decrease of dietary cholesterol absorption and thereby induced a hypocholesterolemic effect on hamsters fed a high cholesterol diet, but did not interfere with the ileal transport of endogenous bile salts.

\section{Materials and Methods}

1) General - Infrared (IR) and nuclear magnetic resonance (NMR) spectra were obtained as described previously. ${ }^{9}$ Thin-layer chromatography (TLC), ${ }^{10)}$ radio-TLC, ${ }^{10}$ ) gasliquid chromatography (GLC), ${ }^{10}$ ) highperformance liquid chromatography (HPLC), ${ }^{11}$ and determination of radioactivity ${ }^{10)}$ were carried out as described previously.

2) Preparation of Ursodeoxycholylcysteic Acid - To a solution of UDCA (4.0 g) dissolved in dioxane $(20 \mathrm{ml})$ containing $n$ butylamine $(2.5 \mathrm{ml})$ was added ethyl chlorocar- 
bonate $(1.0 \mathrm{ml})$ at $10^{\circ} \mathrm{C}$.

After $15 \mathrm{~min}$, a solution of cysteic acid (1.95 g) in $1 \mathrm{~N} \mathrm{NaOH}(14 \mathrm{ml})$ was added at once and the reaction mixture was rapidly stirred for 15 min. Sodium hydroxide was added to give $\mathrm{pH}$ 8-9 (phenolphthalein). The solution was then evaporated to dryness under a reduced pressure. The residue was dissolved in boiling ethanol ( 40 $\mathrm{ml}$ ) and the solution was filtered. The filtrate was diluted with ethyl acetate to give incipient cloudness, and the solution left to stand overnight at $0{ }^{\circ} \mathrm{C}$. The resulting crystalline material was collected by filtration and recrystallized from waterethanol to give crystals $(3.8 \mathrm{~g})$ of sodium salt of UDC-cysA. $\mathrm{mp}>300^{\circ} \mathrm{C}$; IR $(\mathrm{KBr}): 3400(\mathrm{OH})$, $1650(\mathrm{CONH}), 1600$ (COONa), 1520 (CONH), 1400, $1200\left(\mathrm{SO}_{3} \mathrm{Na}\right), 1050 ; \mathrm{NMR}\left(\mathrm{D}_{2} \mathrm{O}\right) \delta: 0.71$ (s, 3H, 18- $\left.\mathrm{CH}_{3}\right), 0.97\left(\mathrm{~s}, 3 \mathrm{H}, 19-\mathrm{CH}_{3}\right), 0.98$ (d, $\left.J=8.06 \mathrm{~Hz}, 3 \mathrm{H}, 21-\mathrm{CH}_{3}\right), 3.25\left(\mathrm{dd}, J_{1}=14.56\right.$ $\left.\mathrm{Hz}, J_{2}=3.57 \mathrm{~Hz}, 1 \mathrm{H}, 1^{\prime}-\mathrm{CH}_{2}-\mathrm{SO}_{3} \mathrm{Na}\right), 3.37$ $\left(\mathrm{dd}, J_{1}=14.56 \mathrm{~Hz}, J_{2}=3.57 \mathrm{~Hz}, 1 \mathrm{H}, 1^{\prime}{ }^{\prime} \mathrm{CH}_{2}-\right.$ $\left.\mathrm{SO}_{3} \mathrm{Na}\right), 4.50\left(\mathrm{dd}, J_{1}=8.98 \mathrm{~Hz}, J_{2}=3.67 \mathrm{~Hz}\right.$, $\left.1 \mathrm{H}, \quad 2^{\prime}-\mathrm{CH}-\mathrm{NH}\right)$; FAB-HR-MS:Calcd. for $\mathrm{C}_{27} \mathrm{H}_{43} \mathrm{O}_{8} \mathrm{NSNa}_{2}+\mathrm{H}^{+}=588.2583$; Found, 588.2581 .

3) Labeled Compounds - $\left[11,12-{ }^{3} \mathrm{H}\right] U D C-$ cysA (sp act $0.87 \mathrm{MBq} / \mathrm{mg}$ ) was prepared from $\left[11,12-{ }^{3} \mathrm{H}\right] \mathrm{UDCA}$ (Daiichi Kagaku Yakuhin, Tokyo, Japan) in the same manner as described above for the unlabeled UDC-cysA.

$\left[24-{ }^{14} \mathrm{C}\right]$ Cholyltaurine (sp act $0.17 \mathrm{MBq} / \mathrm{mg}$ ) was prepared from $\left[24-{ }^{14} \mathrm{C}\right]$ cholic acid (NEN, MA, U.S.A.) according to the method as described previously. ${ }^{12)}$

$\left[4-{ }^{14} \mathrm{C}\right]$ Sitosterol (sp act $2.05 \mathrm{GBq} / \mathrm{mmol}$ ) and $\left[1,2-{ }^{3} \mathrm{H}\right]$ cholesterol $(2220 \mathrm{GBq} / \mathrm{mmol})$ were purchased from Amersham (Buckinghamshire, England) and NEN (MA, U.S.A.), respectively.

Radiochemical purity of the labeled compounds were better than $99.0 \%$ as determined by radio-TLC.

4) Feeding Studies — Male golden Syrian hamsters weighing $80-100 \mathrm{~g}$ (obtained from Hiroshima Experimental Animal Suppliers, Hiroshima, Japan) were maintained on a commercial rodent chow which contained $24.6 \%$ protein, $5.6 \%$ lipids, $52.3 \%$ carbohydrate, $6.4 \%$ ash, $3.1 \%$ fiber and $8.0 \%$ water as the standard diet. Three days after arrival, the hamsters were divided into 4 groups. The first group was maintained on the rodent chow. The other three groups received the same diet supplemented with either $0.1 \%$ UDC-cysA, $0.1 \%$ cholesterol, or both $0.1 \%$ UDC-cysA and $0.1 \%$ cholesterol. The animals were fed these experimental diets for 33 d. At the end of the experimental period, the hamsters were fasted for $24 \mathrm{~h}$. They were anaesthetized with ether and blood was collected from heart. The liver was then rapidly excised and weighed. The gallbladder was resected, and the gallbladder bile was immediately extracted with ethanol.

5) Measurement of Cholesterol Absorption - On the 29th day of the experimental period, $\left[1,2-{ }^{3} \mathrm{H}\right]$ cholesterol $(0.4 \mu \mathrm{g})$ and [4${ }^{14} \mathrm{C}$ ] sitosterol $(0.5 \mu \mathrm{g})$ suspended in $1 \mathrm{ml}$ of saline with Tween 80 were introduced directly into the stomach of 4 hamsters of each group by stomach tube. Feces were collected for $3 \mathrm{~d}$ after the administration of the labeled sterols, pooled for each hamster and lyophilized. The lyophilized feces were extracted with $n$-hexane under reflux for $6 \mathrm{~h}$, and radioactivity in an aliquot of the extract was assayed. Cholesterol absorption (\%) was calculated as [1-(the ratio of the fecal ${ }^{3} \mathrm{H}$ and ${ }^{14} \mathrm{C} /$ the ratio of the administered ${ }^{3} \mathrm{H}$ and $\left.\left.{ }^{14} \mathrm{C}\right)\right] \times 100$.

6) Measurement of Serum and Liver Cholesterol Levels - Serum cholesterol levels were determined with the enzymatic kit (BoehringerMannheim GmbH, Mannheim, Germany).

Liver cholesterol levels were measured by GLC. A part of liver (100-200 mg) was lyophilized, grained, and extracted with $n$-hexane. $5 \alpha$ Cholestane was added as an internal standard at the beginning of the extraction. Quantitation of free cholesterol in an aliquot of the hexane extract was carried out by GLC as the trimethylsilyl ether derivative using a HP-1 capillary column $(25 \mathrm{~m} \times 0.2 \mathrm{~mm}$ i.d., Hewlett-Packard, Palo Alto, U.S.A.). Another aliquot of the extract was evaporated to dryness under $\mathrm{N}_{2}$ and the residue was saponified under reflux with $5 \%$ ethanolic $\mathrm{KOH}$ for $1 \mathrm{~h}$, and the saponification mixture was extracted with $n$-hexane after dilution with water. Quantitation of total cholesterol in the hexane extract was achieved by GLC as described above for the determination of free 
cholesterol.

7) Analysis of Biliary Bile Salts - The ethanol extract of the gallbladder bile was dried under $\mathrm{N}_{2}$. The residue was dissolved in methanol and the solution was passed through $0.45 \mu \mathrm{m}$ filter. Quantitative and qualitative analysis of bile salts in the filtrate was achieved by HPLC. The column used was a TSK-GEL ODS-80TM (25 $\mathrm{cm} \times 6 \mathrm{~mm}$ i.d., Toso, Tokyo, Japan). The eluting solvent was methanol-20 mM sodium phosphate buffer-acetonitrile-distilled water $(20 / 5 / 3 / 1)$ and the flow rate was $1.0 \mathrm{ml} / \mathrm{min}$. The bile salts were detected by a UV detector ( 205 $\mathrm{nm})$.

8) Transport Studies — Everted ileal sacs 7 $\mathrm{cm}$ were prepared from young fasted male hamsters weighing $80-100 \mathrm{~g}$ according to the technique reported by Wilson and Wiseman. ${ }^{13)}$

Three types of experiments were performed. In the first experiment, the sacs were filled with the solution of $\left[24-{ }^{14} \mathrm{C}\right]$ cholyltaurine $(0.2 \mu \mathrm{mol})$ dissolved in $1 \mathrm{ml}$ of Krebs-Ringer bicarbonate buffer ( $\mathrm{pH} 7.4$ ) containing $0.3 \%$ glucose and were placed in $10 \mathrm{ml}$ of the same solution. They were incubated with continuous shaking in an atmosphere of $95 \% \mathrm{O}_{2}$ and $5 \% \mathrm{CO}_{2}$ at $37{ }^{\circ} \mathrm{C}$ for $1 \mathrm{~h}$. At the end of the incubation, the serosal solution was weighed and the concentrations of the ${ }^{14} \mathrm{C}$-labeled bile salt in the mucosal and serosal compartments were determined by the measurement of radioactivity. The second and third experiments were performed in the same manner as that of the first experiment except the buffer solution which contained both $\left[24-{ }^{14} \mathrm{C}\right]$ cholyltaurine $(0.2 \mu \mathrm{mol} / \mathrm{ml})$ and $\left[11,12-{ }^{3} \mathrm{H}\right] \mathrm{UDC}$ cysA in the initial concentrations of $0.2 \mu \mathrm{mol} / \mathrm{ml}$ and $0.4 \mu \mathrm{mol} / \mathrm{ml}$, respectively.

9) Distribution Studies — Five hamsters weighing $80-100 \mathrm{~g}$ received oral administration of $\left[11,12-{ }^{3} \mathrm{H}\right] \mathrm{UDC}$-cysA $(1.1 \mathrm{mg})$ that was dissolved in $0.5 \mathrm{ml}$ of saline. Each hamster was placed in an individual cage and feces and urine were collected separately. The animals were killed by exsanguination at different time intervals after the administration of the labeled bile salt. Liver was excised, blotted on filter papers, weighed, homogenized, and dried by lyophilization.

Stomach, small intestine, cecum, large intes- tine, and other organs and tissues were excised with their contents, soaked in saline, homogenized, and dried by lyophilization. The lyophilized organs or tissues were extracted with a mixture $(15: 1)$ of ethanol and concentrated $\mathrm{NH}_{4} \mathrm{OH}$ in a Sohxlet apparatus for $6 \mathrm{~h}$. The extract was evaporated to dryness under $\mathrm{N}_{2}$ and radioactivity of the residue was determined. The feces were also lyophilized, extracted with the mixture of ethanol and $\mathrm{NH}_{4} \mathrm{OH}$, evaporated, and counted for radioactivity. Aliquots of blood, gallbladder bile, and urine were also counted for radioactivity.

10) Identification of Metabolites — Labeled compounds excreted in the gallbladder bile of the hamsters received $\left[11,12-{ }^{3} \mathrm{H}\right] \mathrm{UDC}$-cysA were analyzed by HPLC. The bile sample was chromatographed with unlabeled UDC-cysA and the glycine and taurine conjugates of UDCA and chenodeoxycholic acid. Each band of the unlabeled authentic standards was collected and the radioactivity was measured. In addition, the radioactivity of $1 \mathrm{~min}$ fraction between bands was assayed.

Labeled compounds excreted in the feces from the hamsters received $\left[11,12-^{3} \mathrm{H}\right] U D C$-cysA were analyzed by radio-TLC.

11) Calculations — The results of quantitative analyses were expressed as mean \pm S.D. The significance of the difference among the groups was calculated with Anova of Stat View (Brain Power Inc., CA, U.S.A.)

\section{Results}

The effects of feeding the diets supplemented with either UDC-cysA, or cholesterol, or both cholesterol and UDC-cysA on body weight gain and liver weights are shown in Table I. There was no difference in body weight gain and liver weights among the groups at the end of the experimental period.

Cholesterol concentrations in the serum and liver in four groups of hamsters with different feeding patterns are shown in Table II. Serum and liver cholesterol levels were significantly higher in hamsters fed the $0.1 \%$ cholesterol diet than in hamsters fed the standard diet. Addition of UDC-cysA to the cholesterol-enriched diet 
reduced the elevation of serum and liver cholesterol levels caused by feeding cholesterol. However, supplementation with UDC-cysA to the standard diet did not show any significant change in serum and liver cholesterol levels.

Table III shows intestinal absorption of cholesterol in four groups of hamsters with different feeding patterns. The rate of cholesterol absorption in hamsters fed the diet supplemented both cholesterol and UDC-cysA was significantly lower than in hamsters fed the cholesterolenriched diet.

The results of the biliary bile salt analysis in four groups of hamsters fed different diets are shown in Table IV. There was no evidence for the presence of the conjugates of UDCA including UDC-cysA in the bile even of hamsters fed the diet supplemented with UDC-cysA.

Figure 1 presents results of experiments designed to determine whether UDC-cysA can be actively transported by everted hamster gut sacs and whether the bile salt bearing two negative charges can inhibit the everted gut sac transport of cholyltaurine. Under the employed condition ( $\mathrm{pH} 7.4$ ), serosal to mucosal ratios of UDC-cysA in excess of unity were never observed, indicating that the dibasic bile salt is not transported, and the final concentration ratios of cholyltaurine were not changed in the coexistense of UDC-cysA, indicating that transport of cholyltaurine was not inhibited by UDC-cysA.

Figure 2 depicted the time course of radioactivity excreted in feces and urine from a hamster received oral administration of $[11,12$ ${ }^{3} \mathrm{H}$ ]UDC-cysA. More than $50 \%$ of the administered radioactivity was recovered in the feces within $12 \mathrm{~h}$. No radioactivity was found in the urine during the experimental period.

Table $\mathrm{V}$ shows the tissue distribution of radioactivity in hamsters fed the labeled UDC-cysA.

TABLE I. Effect of Feeding Diets Containing Either UDC-cysA, Cholesterol or Both on Body Weight Gain and Liver Weights in Hamsters

\begin{tabular}{lcccc}
\hline \hline Groups & Control & UDC-cysA & Cholesterol & Cholesterol + UDC-cysA \\
\hline $\begin{array}{l}\text { Weight gain }(\mathrm{g}) \\
\begin{array}{l}\text { Liver weight at the end } \\
\text { of the experiment }(\mathrm{g})\end{array}\end{array}$ & $57.5 \pm 4.2$ & $58.3 \pm 14.0$ & $65.0 \pm 7.7$ & $61.7 \pm 6.1$ \\
\hline
\end{tabular}

Values are means \pm S.D. for 7 animals.

TABLE II. Effect of Feeding Diets Containing Either UDC-cysA, Cholesterol or Both Cholesterol and UDC-cysA on Serum and Liver Cholesterol Levels in Hamsters

\begin{tabular}{lrrrr}
\hline Groups & Control & UDC-cysA & Cholesterol & Cholesterol + UDC-cysA \\
\hline Serum (mg/dl) & & & & \\
$\quad$ Total cholesterol & $143.0 \pm 29.7$ & $137.4 \pm 24.1$ & $219.3 \pm 42.2^{a)}$ & $144.3 \pm 27.2$ \\
$\quad$ Free cholesterol & $45.6 \pm 12.0$ & $42.3 \pm 7.4$ & $77.0 \pm 23.8^{a}$ & $45.4 \pm 9.4$ \\
Liver (mg/g liver) & & & & \\
Total cholesterol & $0.87 \pm 0.27$ & $0.87 \pm 0.27$ & $8.41 \pm 3.38^{a)}$ & $2.12 \pm 1.92$ \\
Free cholesterol & $0.12 \pm 0.06$ & $0.22 \pm 0.32$ & $1.85 \pm 1.06^{a)}$ & $0.14 \pm 0.09$ \\
\hline
\end{tabular}

Values are means \pm S.D. for 6 animals. a) $p<0.001$, versus other groups.

TABLE III. Effect of Feeding Diets Containing Either UDC-cysA, Cholesterol or Both Cholesterol and UDC-cysA on Intestinal Cholesterol Absorption in Hamsters

\begin{tabular}{|c|c|c|c|c|}
\hline Groups & Control & UDC-cysA & Cholesterol & Cholesterol + UCD-cysA \\
\hline Cholesterol absorption $(\%)$ & $79.2 \pm 5.2$ & $77.3 \pm 4.2$ & $83.5 \pm 0.8$ & $68.4 \pm 2.4^{a, b)}$ \\
\hline
\end{tabular}

Values are means \pm S.D. for 4 animals. a) $p<0.0001$, versus cholesterol. b) $p<0.02$, versus control. 
TABLE IV. Bile Salt Composition of Hamsters Fed Different Diets

\begin{tabular}{lcccc}
\hline \hline $\begin{array}{l}\text { Groups } \\
\text { Bile salt }\end{array}$ & Control & UDC-cysA & Cholesterol & Cholesterol + UDC-cysA \\
\hline UDC-cysA & & & $(\%)$ & N.D. \\
UDC-tau & N.D. & N.D. & N.D. & N.D. \\
UDC-gly & N.D. & N.D. & N.D. & N.D. \\
C-tau & N.D. & N.D. & N.D. & $18.0 \pm 4.0$ \\
C-gly & $31.4 \pm 2.2$ & $25.8 \pm 6.4$ & $29.0 \pm 3.8$ & $14.4 \pm 4.2$ \\
CDC-tau & $26.2 \pm 5.5$ & $20.1 \pm 3.0$ & $18.5 \pm 5.9$ & $34.1 \pm 7.8$ \\
CDC-gly & $19.2 \pm 4.3$ & $25.4 \pm 4.8$ & $14.7 \pm 2.2$ & $22.2 \pm 4.9$ \\
DC-tau & $14.7 \pm 2.4$ & $17.6 \pm 5.8$ & $7.4 \pm 3.2$ & $4.6 \pm 2.0$ \\
DC-gly & $4.8 \pm 2.0$ & $6.0 \pm 2.4$ & $4.6 \pm 2.0$ & $6.7 \pm 1.6$ \\
\hline
\end{tabular}

Values are means \pm S.D. for 7 animals. N.D., not detected; UDC-tau, ursodeoxycholyltaurine; UDC-gly, ursodeoxycholylglycine; C-tau, cholyltaurine; C-gly, cholylglycine; CDC-tau, chenodeoxycholyltaurine; CDC-gly, chenodeoxycholylglycine; DC-tau, deoxycholyltaurine; DC-gly, deoxycholylglycine.

The radioactivity was found in the gastrointestinal tract and hepatobiliary system, but scarcely detected in other organs and tissues.

Table VI shows the distribution of radioactivity in the biliary labeled bile salts following oral administration of $\left[11,12-{ }^{3} \mathrm{H}\right] U D C$-cysA. The occurrence of the administered $[11,12-$ ${ }^{3} \mathrm{H}$ ]UDC-cys $\mathrm{A}$ in a trace amount $(2.3 \%$ of the biliary radioactivity, $0.03 \%$ of the administered radioactivity) was observed only in the first $1 \mathrm{~h}$ sample but not in other bile samples. The labeled bile salts in the bile were identified as taurine and

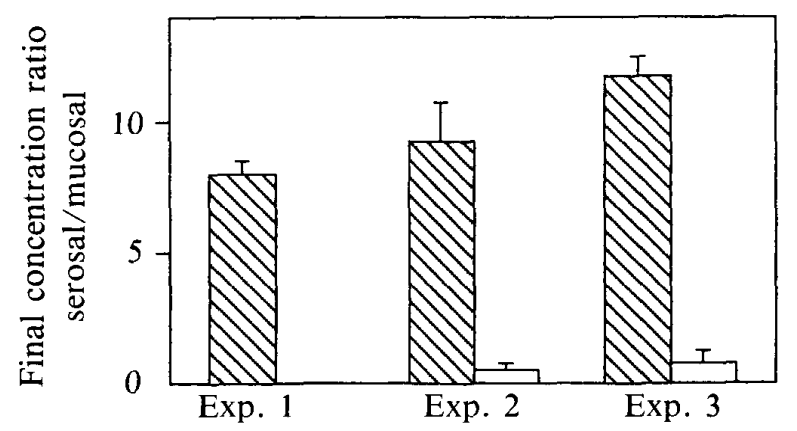

Fig. 1. Transport of UDC-cysA and Its Effect on Transport of Cholyltaurine by Everted Gut Sacs

Batched columns are the ratios of cholyltaurine concentration and the open columns are the ratios of UDC-cysA concentration. Initial concentration of cholyltaurine is 0.2 $\mu \mathrm{mol}$ per $\mathrm{ml}$ in both the serosal and mucosal compartments in all experiment and initial concentrations of UDC-cysA are $0,0.2$ and $0.4 \mu \mathrm{mol}$ per $\mathrm{ml}$ in both the serosal and mucosal compartments in experiments 1,2 , and 3 , respectively. glycine conjugates of either UDCA or chenodeoxycholic acid. The proportion of the conjugates of UDCA decreased during the following hours, while the proportion of the conjugates of chenodeoxycholic acid increased in a complementary fashion.

Table VII shows the distribution of the labeled compounds in the feces collected during $48 \mathrm{~h}$ after oral administration of $\left[11,12-{ }^{3} \mathrm{H}\right] \mathrm{UDC}$ cysA. All radioactivity was found as unconjugated bile acids. The major labeled bile acid in the feces was identified as lithocholic acid.

\section{Discussion}

The present study in hamsters demonstrates

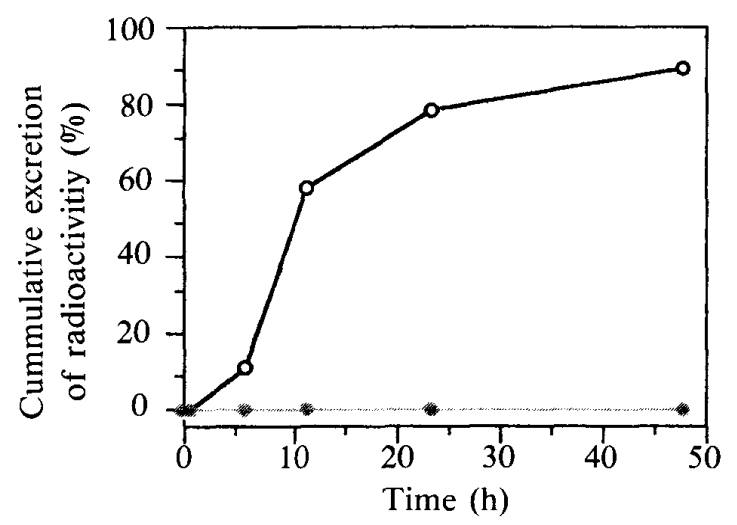

Fig. 2. Fecal $(O)$ and Urinary (fil) Excretion of Radioactivity in a Hamster after Oral Administration of $\left[{ }^{3} \mathrm{H}\right] \mathrm{UDC}$-cysA 
TABle V. Tissue Distribution of Radioactivity in Hamsters after Oral Administration of [ $\left.{ }^{3} \mathbf{H}\right]$ UDC-cysA

\begin{tabular}{|c|c|c|c|c|c|}
\hline \multirow{2}{*}{ Tissues } & \multicolumn{5}{|c|}{ Time after administration (h) } \\
\hline & 1 & 6 & 12 & 24 & 48 \\
\hline & \multicolumn{5}{|c|}{ ( $\%$ of the administered radioactivity) } \\
\hline Stomach & 57.0 & N.D. & N.D. & N.D. & N.D. \\
\hline Liver & N.D. & 2.1 & 1.6 & 2.2 & 1.1 \\
\hline Gallbladder bile & 1.3 & 5.7 & 1.5 & 1.3 & 0.2 \\
\hline Small intestine & 21.1 & 19.8 & 16.6 & 6.1 & 4.3 \\
\hline Cecum & 16.3 & 17.1 & 9.1 & 3.6 & 1.3 \\
\hline Large intestine & 4.0 & 43.6 & 12.5 & 8.3 & 3.1 \\
\hline
\end{tabular}

TABLE VI. Distribution of Radioactivity in Biliary Bile Salts Following Administration of $\left[{ }^{3} \mathrm{H}\right]$ UDC-cysA to Hamsters

\begin{tabular}{|c|c|c|c|c|}
\hline \multirow{2}{*}{ Bile salts } & \multicolumn{4}{|c|}{ Time after administration (h) } \\
\hline & 1 & 6 & 24 & 48 \\
\hline & \multicolumn{4}{|c|}{ ( $\%$ of the biliary radioactivity) } \\
\hline UDC-cysA & 2.3 & N.D. & N.D. & N.D. \\
\hline UDC-tau & 21.1 & 24.6 & 62.2 & 1.5 \\
\hline UDC-gly & 68.5 & 35.2 & 3.6 & 3.2 \\
\hline CDC-tau & 2.0 & 16.4 & 35.3 & 30.8 \\
\hline CDC-gly & 6.1 & 23.8 & 58.9 & 64.5 \\
\hline
\end{tabular}

UCD-tau, ursodeoxycholyltaurine; UDC-gly, ursodeoxycholylglycine; CDC-tau, chenodeoxycholyltaurine; CDC-gly, chenodeoxycholylglycine.

that addition of UDC-cysA to the cholesterolenriched diet reduced the elevation of serum and liver cholesterol concentrations caused by feeding cholesterol (Table II).

We had postulated that UDC-cysA, the chemically synthesized bile salt containing two negative charges, inhibits the intestinal absorption of endogenous bile salts. In contrast to our expectation, this study shows that UDC-cysA did not interfere with the active transport of cholyltau-

TABLE VII. Distribution of Radioactivity in the Fecal Bile Acids Following Oral Administration of $\left[11,12-{ }^{3} \mathrm{H}\right]$ UDCcysA to Hamsters

\begin{tabular}{lc}
\hline \hline Bile acid & $\begin{array}{c}\text { Percentage of } \\
\text { radioactivity in the feces }\end{array}$ \\
\hline UDC-cysA and other & \\
conjugated bile acids & N.D. \\
Chenodeoxycholic acid & 4.4 \\
UDCA & 7.1 \\
Lithocholic aicd & 73.9 \\
3-Oxo-5 $\beta$-cholanoic acid & 14.6 \\
\hline
\end{tabular}

rine in everted gut sac experiments (Fig. 1). It has been known that in an ileal active transport system of bile salts a single negative charge on the side chain is essential for activity. ${ }^{7,8,14)}$ The transport of bile salts containing two negative charges increases when $\mathrm{pH}$ is decreased, since lower $\mathrm{pH}$ increases the concentration of singly charged species of the dibasic bile salts. $\left.{ }^{8}\right)$ Based on the same reason, bile salts bearing two negative charges are more effective competitors for ileal bile salt transport at lower $\mathrm{pH} .^{7)}$ It seems, therefore, likely that in the presently employed condition $(\mathrm{pH}$ of the incubation mixture was 7.4), the singly charged species of UDC-cysA was minimal, resulting in the minimal interference on the transport of cholyltaurine. Further support for this notion was provided by the demonstration that in the distribution study (Table IV, $\mathrm{V}$, Fig. 1) using intact hamsters orally administered UDC-cysA was hardly absorbed from the intestinal tract and quickly excreted into feces.

After the oral administration of ${ }^{3} \mathrm{H}$-labeled UDC-cysA to intact hamsters, the biliary labeled 
compounds were taurine- and glycine-conjugates of UDCA and chenodeoxycholic acid rather than UDC-cysA alone (Table VI). The present study also shows that the fecal labeled compounds were present in the unconjugated form (Table VII). These results indicate that UDC-cysA, the cysteic acid conjugate of UDCA, like taurine- and glycine-conjugates, undergoes bacterial deconjugation to give unconjugated UDCA during passage through the intestinal tract, and that UDCA formed and its bacterial metabolites are reabsorbed from the intestine, conjugated with either taurine or glycine by the liver, and excreted into the bile. There are two possible routes for the conversion of UDCA to chenodeoxycholic acid. One in the pathway including lithocholic acid as an intermediate. It is well-known that UDCA is dehydroxylated to form lithocholic acid by the action of intestinal microorganisms, ${ }^{15}$ ) and lithocholic acid absorbed is hydroxylated to give chenodeoxycholic acid during a single passage through the hamster liver. ${ }^{16)}$ Another possible route for the formation of chenodeoxycholic acid from UDCA includes 7-ketolithocholic acid as an intermediate. The bacterial conversion of UDCA into 7-ketolithocholic acid was demonstrated by a number of investigaters, ${ }^{17-19)}$ and 7ketolithocholic acid could be metabolized into chenodeoxycholic acid by the action of bacterial and hepatic dehydrogenases. ${ }^{20,21)}$ In any case, the relatively low distribution of radioactivity in the bile (Table V), in agreement with the present results for the very rapid recovery of label in the feces (Fig. 2), indicates the inefficient absorption of not only UDC-cysA but also its metabolites.

Hence the hypocholesterolemic activity of dietary UDC-cysA is not attributed to the effects on bile salt metabolism but is thought to be the effect on intestinal absorption of cholesterol. Indeed, the present study clearly shows that administration of UDC-cysA decreased cholesterol absorption in hamsters in comparison with the cholesterol-enriched diet group (Table III). The mechanism for the inhibitory effect of UDCAcysA on cholesterol absorption is not obvious. Studies on the mechanism are being conducted in this laboratory and the details will be reported elsewhere in the near future.

\section{References}

1) I. Makino, K. Shinozuka, K. Yoshino, and S. Nakagawa: Dissolution of cholesterol gallstones by ursodeoxycholic acid, Jpn. J. Gastroenterol., 72, 690-702 (1975).

2) R. Poupon, R. E. Poupon, Y. Calmus, Y. Chretien, R. Ballet, and F. Darnis: Is ursodeoxycholic acid an effective treatment for primary biliary cirrhosis? Lancet, I, 834-836 (1987).

3) M. Ponz de Leon, N. Carulli, P. Loria, R. Iori, and F. Zironi: Cholesterol absorption during bile acid feeding: effect of ursodeoxycholic acid (UDCA) administration, Gastroenterol., 78, 214-219 (1980).

4) R. F. Raicht, B. I. Cohen, A. Sarwal, and M. Takahashi: Ursodeoxycholic acid: effects on sterol metabolism in rats, Biochim. Biophys. Acta, 531, 1-8 (1978).

5) A. Stiehl, P. Czygan, B. Kommerell, H. J. Weis, and K. H. Holtermuller: Ursodeoxycholic acid versus chenodeoxycholic acid: comparison of their effects on bile acid and bile lipid composition in patients with cholesterol gallstones, Gastroenterol., 75, 1016-1020 (1978).

6) L. Lack and I. M. Weiner: Intestinal bile salt transport: structure-activity relationships and other properties, Am. J. Physiol., 210, 1142-1152 (1966).

7) L.Lack and I. M. Weiner: The ileal bile salt transport system: effect of the charged state of the substrate on activity, Biochim. Biophys. Acta, 135, 1065-1068 (1967).

8) L. Lack, J. T. Walker, and G. D. Singletary: Ileal bile salt transport: in vivo studies of effect of substrate ionozation on activity, Am. J. Physiol., 219, 487-490 (1970).

9) K. Kihira, M. Yoshii, A. Okamoto, S. Ikawa, H. Ishii, and T. Hoshita: Synthesis of new bile salt analogues, sodium $3 \alpha, 7 \alpha$-dihydroxy-5 $\beta$-cholane-24-sulfonate, $J$. Lipid Res., 31, 1323-1326 (1990).

10) M. Une, K. Yamanaga, E. H. Mosbach, K. Tsujimura, and T. Hoshita: Metabolism of $7 \beta$-alkyl chenodeoxycholic acid analogs and their effect on cholesterol metabolism in hamsters, J. Lipid Res., 31, 1015-1021 (1990).

11) M. Une, T. Goto, K. Kihira, T. Kuramoto, K. Hagiwara, T. Nakajima, and T. Hoshita: Isolation and identification of bile salts conjugated with cysteinolic acid from bile of the red seabream, Pagrosomus major, J. Lipid Res., 32, 1619-1623 (1991).

12) T. Hoshita, N. Harada, I. Morita, and K. Kihira: Intestinal absorption of bile alcohols, J. Biochem, 90, $1363-1369$ (1981).

13) T. H. Wilson and G. Wiseman: The use of sacs of everted small intestine for the study of the transference of substances from the mucosal to the serosal surface, $J$. Physiol., 123, 116-125 (1954).

14) T. S. Low-Beer, M. P. Tyor, and L. Lack: Effects of sulfation of taurolithocholic and glycolithocholic acids on their intestinal transport, Gastroenterol., 50, 721 726 (1969). 
15) B. A. White, R. J. Fricke, and P. B. Hylemon: $7 \beta-$ Dehydroxylation of ursodeoxycholic acid by whole cells and cell extracts of the intestinal anaerobic bacterium, Eubacterium species V.P.I. 12708, J. Lipid Res., 23, $145-153$ (1982).

16) S. Emerman and N. B. Javitt: Metabolism of taurolithocholic acid in the hamster, J. Biol. Chem., 242, $661-664$ (1966).

17) I. A. Macdonald, D. M. Hutchison, and T. P. Forrest: Formation of urso- and ursodeoxy-cholic acids from primary bile acids by Clostridium absonum, J. Lipid Res., 22, 458-466 (1981).

18) I. A. Macdonald, Y. P. Rochon, D. M. Hutchison, and L. V. Holdeman: Formation of ursodeoxycholic acid from chenodeoxycholic acid by a $7 \beta$-hydroxysteroid dehydrogenase-elaborating Eubacterium aerofaciens strain cocultured with $7 \alpha$-hydroxysteroid dehydrogenaseelaborating organisms, Appl. Environ. Microbiol., 44, 1187-1195 (1982).

19) J. D. Sutherland and I. A. Macdonald: The metabolism of primary, 7-oxo, and 7 $\beta$-hydroxy bile acids by Clostridium absonum, J. Lipid Res., 23, 726-732 (1982).

20) H. Higashi, T. Setoguchi, and T. Kazuki: Interconversion between chenodeoxycholic acid and ursodeoxycholic acid in anaerobic cultures of intestinal bacteria, and reduction of 7-ketolithocholic acid to both bile acids, Acta Hepatol. Jpn., 19, 803 (1978).

21) H. Fromm, G. L. Carlson, A. F. Hofmann, S. Farivar, and P. Amin: Metabolism in man of 7-ketolithocholic acid: precursor of cheno- and ursodeoxycholic acids, Am. J. Physiol., 239, G161-G166 (1980). 